\title{
КОМПЬЮТЕРНЫЙ ЖАРГОН В ПРОЦЕССЕ ОБУЧЕНИЯ \\ ИНОСТРАННЫХ СТУДЕНТОВ РУССКОМУ ЯЗЫКУ КАК ЯЗЫКУ СПЕЦИАЛЬНОСТИ
}

\section{COMPUTER JARGON IN THE PROCESS OF TEACHING RUSSIAN TO FOREIGN STUDENTS}

\author{
СВЕТЛАНА ЗАБОРОВСКАЯ
}

\begin{abstract}
This article raises the question of the reasonableness of introducing the basics of computer jargon when teaching specialist language courses for foreign students of preparatory faculties (technical language).

Светлана Заборовская, Харьковский национальный университет радиоэлектроники, Харьков - Украина.
\end{abstract}

Появление компьютеров и бурное развитие цифровых технологий привели к созданию особого лингвокультурного феномена - профессионального подъязыка компьютерных технологий, или компьютерного жаргона (КЖ). Термином „компьютерный жаргон” в данной работе обозначается „некодифицированный профессиональный язык компьютерщиков и программистов, а также людей, чья профессиональная деятельность тесно связана с компьютерами и их использованием" 1 . Компьютеризация различных сторон человеческой деятельности делает компьютерный жаргон социально активным, помещая его в фокус социального влияния. Кроме того, „из всех других профессиональных жаргонов по своей коммуникативной роли" он явно выделяется „не только как средство внутригруппового общения, но и как своеобразный символ времени" 2 . Всемирная сеть способствует „обогащению” компьютерного жаргона новыми лексемами. Постепенное расширение границ профессионального общения превращает его в групповой, корпоративный жаргон, число носителей которого растет

${ }^{1}$ Н.В. В и н о г р а д о в а, Номинативная функиия русского компьютерного жаргона, [в:] электронный ресурс: http://www.dialog-21.ru/dialog2007/materials/html /VinogradovaN.htm

2 Л.П. К р ы с и н, О некоторых изменениях в русском языке кониа ХХ века, „Исследования по славянским языкам", Сеул 2000, № 5, с. 63-91. 
за счет обычных интернет-пользователей, в особенности молодежи. Поэтому многие лексические элементы КЖ становятся общеупотребительными и понятными, что в дальнейшем, вероятно, приведет к включению их в лексическую систему общелитературного языка.

Традиционно сфера использования любого жаргона - непринужденная неофициальная обстановка. Однако в последние десятилетия исследователями отмечается сильнейшее влияние жаргонной и просторечной языковой среды на русский литературный язык. „Едва ли не основной чертой современного дискурса" называет Е.А. Земская перемещение лексических элементов периферийных систем русского языка (жаргон, разговорные элементы, просторечие) в центр системы. Таким образом, независимо от нашего желания / нежелания жаргон становится своеобразной речевой реалией нашего бытия.

Компьютерный жаргон представляет собой неоднородный в функционально-стилистическом плане пласт лексики. Так, например, О.И. Ермакова выделяет: 1) слова-термины (ок. $17 \%$ от общего числа слов - наименования различных программ, команд, устройств и т. п., связанных с компьютерами, напр.: броузер (от англ. browser 'средство просмотра web-странищ'), онлайновый (режим) (от англ. on-line 'режим работы с непосредственным доступом к сети'); 2) экспрессивно окрашенные слова, которые употребляются для указания принадлежности говорящего к определенной социальной группе (почти 50\% от общего числа слов, напр.: юзер, компутер, аська и пр.); 3) профессионализмы, занимающие промежуточное положение (немногим более $30 \%$, которые не являются экспрессивно нейтральными, но выполняют, прежде всего, номинативную функцию (напр.: коннектиться - от англ. connect 'устанавливать соединение с удаленным ресурсом', oneрационка - 'операционная система') ${ }^{4}$.

B.С. Елистратов считает, что существуют профессиональные термины (терминология) и профессиональный „язык" в широком понимании этого слова, который можно назвать жаргоном, арго, сленгом или диалектом. При этом грань между профессиональным термином и „просто словом” почти всегда нечетка, поскольку „не всякая терминология санкционирована как терминология. Термин - в строгом смысле - атрибут науки, а не всякая профессия имеет научно-тер-

${ }^{3}$ См., например, Л.П. К р ы с и н, О русском языке наших дней, [в:] электронный pecypc: http://language.psu.ru/bin/view.cgi?art=0038\&lang=rus; E.A. 3 е м с к а я, Активные процессы в русском языке последнего десятилетия ХХ века, [в:] электронный pecypc: www.gramota.ru/mag_arch.html?id=49

${ }^{4}$ См. О.И. Е р м а к о в а, Особенности компьютерного жаргона как специфической подсистемы русского языка, [в:] электронный ресурс: www.dialog-21.ru/materials/ archive. asp $? \mathrm{id}=6683 \& \mathrm{y}=2001 \& \mathrm{vol}=6077$ 
минологическое ядро. Хотя его подобие есть всегда. Значит, можно говорить, во-первых, о терминах (манипулятор - 'небольшое вспомогательное устройство для ввода информации в компьютер, перемещением которого по поверхности (столу) контролируется положение курсора на мониторе'), во-вторых, о «нейтральных» профессионализмах (мышь) и, в-третьих, о неких не нейтральных экспрессивных профессиональных жаргонизмах (или арготизмах и проч.: мышатина, мышкодром, мымедром, крысищза и т. д.)"5. Отсутствие четкой границы между жаргонизмами, терминами и профессионализмами нашло свое отражение и в специальных словарях. Например, в Толковом словаре русского языка конца ХХ века. Языковые изменения (1998 г.) находим слова взлом, взломать, взломщик, висеть, виснуть, зависать, зависание, которые помечены как жаргонные. Современные сетевые словари КЖ6 не содержат слов взлом, взломать, взломщик, следовательно, они уже не воспринимаются как жаргонные самими носителями КЖ, хотя довольно активно используются в соответствующих ситуациях общения. Лексемы пользователь, ламер, юзер в Толковом словаре русского языка XX века не имеют помет „жарг.", однако в каждом словаре КЖ присутствуют юзер и ламер, хотя трактовка последнего может варьироваться: 'чайник, возомнивший себя крутым'7 или 'пользователь, который умничает или хвастается своими знаниями, но знаний нет... самовлюбленный пользователь, который никогда не будет ничему учиться' 8 .

Отдельные лексемы компьютерного подъязыка образуют синонимичные пары или ряды, которые могут включать в себя как профессиональную и терминологическую лексику, так и жаргонизмы: материнская плата - мама - мать - материнка, мегабайт - метр - мег - МБ, системный администратор - сисадмин, монитор компьютера - Моня Моник, сетевая плата - сетевуха, программа мгновенного обмена сообщениями ICQ Ай-Сu-Кью - Аська, локальная сеть - локалка - лан - ланка. При отсутствии однословных синонимов в литературном языке для тех или иных реалий компьютерной техники или технологий жаргонные слова используются даже в печатных изданиях соответствующей тематики: „Экзотические комплектующие можно поискать у продавцов подержанного железа9 - железо (жарг.) 'аппаратные средства компьютера

${ }_{5}^{5}$ См. В.С. Е л и с т р а т о в, К проблеме изучения профессиональных языков, [в:] электронный ресурс: http://www.kalanov.ru/elistratovr.html

${ }^{6}$ Например, см.: электронные ресурсы: http://slovar.plib.ru/dictionary/dl3/; http://mirslovarei.com/ksl_A/; http://www.gvorn.narod.ru/zarabotok/ra2xioe/spskz.html; http://www.kmm.ru/ kivok/slov.htm; http://www.profjob.info/slovar/slovar.htm и проч.

7 Электронные ресурс: http://www.kmtn.ru/ kivok/slov.htm

8 Электронные ресурс: http://www.profjob.info/slovar/l.htm

9 “Computer Bild" 2009, no. 5. 
в отличие от программного обеспечения'”10; „Девайс примечателен не только своими характеристиками, но и, в большей степени, эргономикой и внешним видом"11. Слово деъайс (жарг.) восходит к англ. device 'устройство, приспособление - любое устройство, конструктивно законченная техническая система, имеющая определенное функциональное устройство'.

Таким образом, овладение иностранными студентами - будущими специалистами в области информационных технологий - наиболее употребительными лексемами компьютерного жаргона (в первую очередь - словами-терминами и профессионализмами) является необходимым условием формирования речевой компетенции. Кроме того, характерная для ряда жаргонов функция „засекречивания" в компьютерном подъязыке соединяется с контактоустанавливающей функцией и предназначается для распознавания своих в оппозиции „свой - чужой". Использование тех или иных лексем данного жаргона в процессе общения является своеобразным паролем, который дает право на вход в пространство общения „посвященных”. Владение компьютерным жаргоном представляется также престижным и в социальном плане, поскольку „усвоение той его части, которая граничит с компьютерными технологиями, является весьма трудоемким и доступно немногим"12. Иностранный студент, владеющий „специальным" языком компьютерщиков, автоматически становится „своим” среди будущих программистов и инженеров, что, безусловно, положительно влияет на уровень его самооценки и помогает комфортнее чувствовать себя в пространстве русскоязычной профессиональной коммуникации. В специальных технических вузах (например в университете радиоэлектроники) слова компьютерного жаргона используются студентами намного чаще, чем в других учебных заведениях, поскольку компьютерные технологии и Интернет для них не просто средство коммуникации или развлечение, но и будущая специальность. Поэтому иностранные учащиеся, которые 10 месяцев находились в „стерильном" пространстве русского литературного языка и научного стиля речи, в первые месяцы обучения на 1-м курсе вуза могут испытать своего рода лингвистический шок при общении с одногруппниками. Значит, преподаватель русского языка еще на подготовительном факультете должен подготовить иностранных студентов к восприятию специфических лексем, познакомить хотя бы с основными профессионализмами,

10 Толковый словарь русского языка конияа ХХ века. Языковые изменения, Санкт-Петербург, Фолио-пресс, 1998.

11 „Железо" 2009, № 3 .

12 Н.В. В и н о г р а д о в а, Компьютерный сленг и литературный язык: проблемы конкуренции, „Исследования по славянским языкам”, Сеул 2001, № 6, с. 203-216. 
которые наиболее часто используются среди студентов именно этого вуза. Безусловно, семантизация и закрепление новой лексики потребует от педагога определенного уровня профессионализма и креативного мышления. Кроме того, необходимо с особой тщательностью подходить к отбору того минимума слов компьютерного жаргона, который предстоит усвоить иностранным студентам. В качестве текстов-образцов могут быть использованы статьи из различных специализированных журналов, например „Computer Bild”, „Game P1ay”, „Linux Format”, , Компьютерное обозрение” и др., поскольку компьютерный жаргон используется даже в их названиях („Хакер”, ,ЖЖелезо”). Особенность текстов из данных журналов состоит в том, что во многих из них жаргонные слова в предложениях выделяются кавычками, поэтому студент может их легко найти в тексте: „,..видеокарта «потянет» любые современные игры с высокими настройками графики и разгрузит процессор ПК”, „Необходимо записать «болванку», но встроенный «резак» не поддерживает «прожиг» дисков нужного формата". Кроме того, в ряде случаев в одной фразе могут одновременно совмещаться нейтральные слова с их синонимами-жаргонами: „Kлавиатура MacBook Air отличается от «клаb» у большинства других ноутбуков". При необходимости преподаватель может сам „насытить” уже готовые тексты необходимыми профессионализмами или терминами. Однако это потребует от него определенных знаний не только в области компьютерного жаргона, но также в сфере компьютерной и интернет-терминологии. При этом очень важно (подчеркнем еще раз!) не перестараться в отборе действительно нужной компьютерной лексики, поскольку излишнее или бездумное использование иностранцами жаргонных слов может привести к коммуникативным неудачам в профессиональной сфере общения. Поэтому при подготовке курса (или спецкурса) профессиональной лексики для студентов факультетов ИТ преподаватель-русист, как нам кажется, должен работать в тандеме с преподавателями специальных кафедр, которые могут помочь в отборе того лексического минимума, которым необходимо овладеть иностранному студенту для успешной учебы. Вместе с тем целесообразно, вероятно, изучать КЖ в течение всего периода обучения русскому языку в вузе (1-4 курсы), усложняя с каждым годом типы упражнений и добавляя новые слова.

Знакомство иностранных учащихся с КЖ, на наш взгляд, лучше всего начать с работы над словами, которые представляют собой транслитерацию английских слов с сохранением основного значения лексемы. Например: PC, винчестер (winchester), аттачмент (attachment), интерфейс (interface), девайс (device), баг (bug), броузер (browser), скин (skin), бэкап (backup), ґинк (link), ламер (lamer), юзер (user), флуд (flood) 
и пр. Эти слова должны быть уже известны студентам. Теперь им предстоит узнать, что семантика этих лексем в русском языке такая же, как и в английском. Следующим этапом является составление синонимичных пар (или цепочек) с этими словами, напр.: РС - персональныи компьютер, аттачмент - прикрепленный файл, баг - ошибка - глюк, броузер - бродилка, юзер - пользователь, линк - ссылка. Далее, синонимичную цепочку можно дополнить сокращениями (если они существуют), напр.: РС - компьютер - комп, аттачмент - прикрепленный файл - аттач, винчестер - винт, или универбами: выделенная линия - выделенка, системный администратор - сисадмин, локальная сеть - локалка, материнская плата - материнка и пр. При этом преподавателю обязательно необходимо акцентировать внимание студентов на разграничении сферы использования этих синонимов, указывая, например, что слова юзер, баг или бродилка можна употреблять в непринужденной неофициальной обстановке при обсуждении каких-либо профессиональных вопросов со своими одногруппниками или знакомыми на интернет-форумах, а в курсовых работах или рефератах необходимо использовать лексемы пользователь, ошибка, броузер. В заключение важно отметить, что методические приемы, используемые преподавателем для презентации, закрепления и контроля профессиональной лексики компьютерных технологий, а также дозировка и отбор нового материала, на наш взгляд, должны варьироваться исходя из уровня языковой подготовки той или иной учебной группы. При этом изучаемый материал, одной из особенностей которого является игра со словом, дает возможность преподавателю смело вводить различные игровые элементы в структуру урока.

Таким образом, развитие профессионального подъязыка компьютерных технологий и постепенное расширение сферы его употребления, а также переход все большего числа компьютерных жаргонизмов в речевую практику носителей русского языка представляет собой уже свершившийся факт. Более того, компьютеризация общества, которая привела к появлению нового коммуникативного пространства, диктует новый „языковой вкус эпохи" (В.Г. Костомаров), создает новую реальность, обслужить которую без КЖ русский язык оказывается не в состоянии. Все это является неоспоримым аргументом в пользу введения компьютерного подъязыка в программу изучения научного стиля речи для студентов-иностранцев, чья будущая специальность связана с информационными технологиями. 